\title{
(6) OPEN ACCESS \\ Life-course partnership history and midlife health behaviours in a population-based birth cohort
}

\author{
Katherine Keenan, ${ }^{1}$ George B Ploubidis, ${ }^{2}$ Richard I Silverwood, ${ }^{3}$ Emily Grundy ${ }^{1}$
}

\begin{abstract}
- Additional material is published online only. To view please visit the journal online (http://dx.doi.org/10.1136/jech2015-207051).

${ }^{1}$ Department of Social Policy, London School of Economics and Political Science, London, UK

${ }^{2}$ Department of Social Science, UCL Institute of Education, University College London, London, UK

${ }^{3}$ Department of Medical Statistics, London School of Hygiene and Tropical Medicine, London, UK
\end{abstract}

\section{Correspondence to Dr Katherine Keenan, Department of Social Policy, London School of Economics and Political Science, Houghton Street, London WC2A 2AE, UK; \\ k.keenan1@|se.ac.uk}

Received 4 December 2015 Revised 2 May 2016 Accepted 27 July 2016 Published Online First 21 September 2016

\section{ABSTRACT \\ Background Marital and partnership history is strongly} associated with health in midlife and later life. However, the role of health behaviours as an explanatory mechanism remains unclear. The aim of this study was to investigate prospective associations between lifecourse partnership trajectories (taking into account timing, non-marital cohabitation, remarriage and marital transitions) and health behaviours measured in midlife.

Methods We analysed data from the British National Child Development Study, a prospective cohort study that includes all people born in 1 week of March 1958 $(\mathrm{N}=10$ 226). This study included men and women with prospective data on partnership history from age 23 to 42-44 and health behaviours collected at ages 42-46 (2000-2004). Latent class analysis was used to derive longitudinal trajectories of partnership history. We used multivariable regression models to estimate the association between midlife health behaviours and partnership trajectory, adjusting for various early and young adult characteristics.

Results After adjustment for a range of potential selection factors in childhood and early adulthood, we found that problem drinking, heavy drinking and smoking were more common in men and women who experienced divorce or who had never married or cohabited. Women who married later had a lower prevalence of smoking and were less likely to be overweight than those who married earlier. Overall marriage was associated with a higher body mass index. Individuals who never married or cohabited spent less time exercising.

Conclusions Some aspects of partnership history such as remaining unpartnered and experiencing divorce are associated with more smoking and drinking in midlife, whereas marriage is associated with midlife weight gain. Despite these offsetting influences, differences in health behaviours probably account for much of the association between partnership trajectories and health found in previous studies.

\section{INTRODUCTION}

Many studies conducted in different countries and time periods have found that being married is associated with better long-term health outcomes and lower mortality than being unmarried or formerly married. $^{1-4}$ Typically, studies consider current marital status but a measure of longitudinal marital history/biography, which takes into account union timing, multiple transitions and non-marital unions, is important for understanding the development of poor health over the life course. ${ }^{5-9}$ Health disparities according to partnership are commonly attributed to a combination of health selection, health protection and crisis-induced factors, ${ }^{10-12}$ but the precise mechanisms linking partnership and health are not well understood. Studies of causespecific mortality patterns or specific health conditions have provided clues to disease aetiology, ${ }^{13} 14$ showing that the unmarried are more likely to die of external causes, neoplasms and circulatory disease. A recent study using the 1958 British Birth Cohort found that those who had never cohabited or married had worse measures of inflammatory and haemostatic markers, higher prevalence of metabolic syndrome and lower respiratory function. ${ }^{9}$

The extent to which health behaviours might explain these differences in disease risk has been investigated in previous studies, but results have been inconclusive. Studies show that the unmarried have less favourable risk profiles, ${ }^{13}$ and marital transitions precipitate changes in drinking, smoking and diet. ${ }^{15-17}$ However, partnership may have potentially offsetting influences on different health behaviours. For example, those in married or cohabiting relationships tend to have healthier behaviours in terms of smoking, harmful alcohol use and exercise, ${ }^{18}{ }^{19}$ but married individuals are more likely to be overweight or obese. ${ }^{16}{ }^{17}$ Moreover, aspects of health such as weight gain and smoking are correlated within spouses, ${ }^{20}$ suggesting that the beneficial effects of relationships are conditional on individual traits and patterns of assortative mating. In addition, associations may be moderated by gender or age. ${ }^{4} 2122$ Sedentary behaviour is commonly found to be a risk factor for poor health independent of physical activity; however, the association with partnership is inconsistent. ${ }^{23}$

In this study, we explore how health behaviours vary between individuals with different life-course partnership histories. We build on previous research, which summarised marital/cohabitation status over a 21-year period to investigate associations with health biomarkers in midlife. ${ }^{9}$ In this study, our aim is to investigate the associations between life-course partnership trajectories and a wide range of self-reported and objectively measured health behaviours at ages 42-46.

\section{METHODS \\ Data}

Data come from the British National Child Development Study (NCDS), a birth cohort study that comprises all people born in Britain during a single week in March 1958. The 18558 cohort members initially enrolled have been followed up regularly from birth into middle age. ${ }^{24}$ To derive partnership status trajectories, we used four sweeps of the NCDS, $1981 \quad(\mathrm{~N}=12$ 537), 1991 $(\mathrm{N}=11469), 2000 \quad(\mathrm{~N}=11419)$ and 2002-2004 
$(\mathrm{N}=8018)$, when study members were aged $23,33,42$ and $44-$ 46 years, respectively. To control for possible selection into partnership trajectories, we used data from earlier sweeps conducted between 1958 and 1981 (when cohort members were aged 023 years). The analytic sample included participants with at least three valid responses on cohabitation and marriage indicators and complete information on the background confounders (5256 women and 4970 men). The NCDS (1958 birth cohort) has ethical approval from various bodies in the UK for all available data sweeps that were used in this study.

\section{Measures}

Partnership status

We used binary indicators representing whether a participant was married or living with a non-marital partner at each measurement wave. Each of the four measurement waves is thus represented by two indicators (one for marital status and one for cohabitation). We infer divorce/separation from an individual reporting being married at one point in time and not married at the next. Those who become widowed are also included in this group; however, these were very few (68 participants at age 44 reported their status as widowed, $<1 \%$ of the analytical sample). We also included in the model information on whether participants had been remarried by age 44 (see online supplementary appendix table 1 ).

\section{Health behaviours in midlife}

Alcohol use and physical activity were self-reported, and weight, height and waist/hip ratio were measured by a nurse at ages 4446 (2002-2004 sweep). Smoking was self-reported at ages 33 and 42 (1991 and 2000 sweep). We used two indicators of harmful alcohol use: the Alcohol Use Disorders Identification Test (AUDIT), ${ }^{25}$ in which the recommended cut-off of eight identifies problem drinking, and an ordinal measure of frequency of heavy episodic drinking (HED) with categories never, less than monthly, monthly or weekly. HED was defined as consuming six or more standard drinks on one occasion. Smoking was classified into never smoked, ex-smoker or occasional smoker and current smoker. We also used a variable indicating the total years of regular smoking from ages 23 to follow-up at age 42 .

Physical activity was measured using a modified version of the EPIC Physical Activity Questionnaire (EPAQ2) questionnaire, which asked about frequency and time spent in a range of leisure activities, work activities and active travel. ${ }^{26}$ We derived two summary measures of physical activity. The first measure was total hours per week in moderate or vigorous activities (those with a metabolic equivalent of three or more ${ }^{27}$ ). The second measure was weekly hours of sedentary activity (sitting and doing light activities at work, watching TV and using computers). The proportion of respondents with complete and plausible values was $63.3 \%$ for physical activity and $78.1 \%$ for sedentary behaviour.

We dichotomised body mass index (BMI) into 25 or more versus less (ie, being overweight or obese vs normal or underweight), and the waist/hip ratio (WHR) was dichotomised using the recommended cut-offs indicating a substantially increased risk of metabolic complications ( 0.85 for women, 0.90 for men). ${ }^{28}$ To identify co-occurrence, we constructed a summary index indicating the number of poor health behaviours out of six (current smoking, AUDIT Score $>8, \mathrm{BMI} \geq 25$, lowest quintile for physical activity, highest quintile for sedentary behaviour and raised WHR).

\section{Childhood and young adult characteristics}

We included several measures from early life and young adulthood (to age 23) likely to be associated with selection into partnership and later life health behaviours. We adjusted for early life socioeconomic position using a latent summary of serious financial hardship during the last year at age 11, access to household amenities at age 11 , paternal social class at age 7 , number of people per room at age 7 , housing tenure at age 7 and paternal weekly net pay at age 16 (details of this derivation have been published elsewhere). ${ }^{9}$ Health centre attendance during the previous year at age 16 , disability at age 16 and height at age 7 were used as indicators of health status in earlier life. Parental divorce by age 16 was used as an indicator of family disruption, and behavioural problems at age 16 were measured using the Rutter behaviour index. We also included variables measured at age 23: educational attainment, self-rated health, depression, employment status, presence of long-standing disability and height (men only). We adjusted for general cognitive ability measured at age 11 . Finally, we adjusted for self-reported health behaviours prior to partnership: smoking at ages 16 and 23 , and alcohol use, BMI and physical activity at age 23 . All measures were reported by the cohort members or their parents except height at age 7 , which was measured by a medical examination. Descriptive statistics are available in online supplementary appendix tables 2 and 3.

\section{Statistical modelling}

We used latent class analysis (LCA) to derive a longitudinal typology of partnership status. LCA is an approach that can be viewed as an evidence-based approximation that improves a researcher's ability to identify, summarise and communicate complex patterns in longitudinal data ${ }^{29}$ which has been used in a range of applications. ${ }^{30}{ }^{31}$ Within LCA, longitudinal trajectories can be inferred from patterns on observed indicators of marital status and cohabitation measured over time. There were 325 unique response patterns for men and 316 in women. LCA was used to summarise these patterns by creating longitudinal trajectories; their derivations have been described in detail in an earlier publication. ${ }^{9}$

We used the derived longitudinal typologies to investigate the association between partnership trajectories and a range of health-related behaviours in midlife: alcohol use, smoking, BMI and physical activity. We fitted multivariable regression models for each health behaviour in midlife and included as covariates the latent class allocation for partnership trajectory and the other control variables (childhood and young adult characteristics as described above). We include a sample of the Mplus model code in online supplementary material. Number of hours of physical activity and sedentary activity were log-transformed to normalise their distribution before using in linear regression models. Total years of regular smoking was modelled using negative binomial regression due to the large number of zeros in the distribution. The other measures were modelled either using logistic regression (AUDIT Score, BMI $\geq 25$ and raised WHR) or ordinal logistic regression (frequency of HED, smoking and behaviour index).

Selection bias, in the form of incomplete or missing data, is almost ubiquitous in the observational setting of the NCDS, and it is well known that unbiased estimates cannot be obtained without properly addressing the implications of incompleteness. We employed the full information maximum likelihood method, which is naturally incorporated into the generalised latent variable modelling framework. ${ }^{32}$ In this full likelihood context model, parameters and SEs are estimated directly from the 
available data; under the assumption that missingness is at random (MAR) and that the models are correctly specified. ${ }^{33}$ In our analyses, assuming MAR means that all variables that may plausibly be responsible for the missing data mechanism are complete and are included in the model as explanatory variables or intermediate outcomes. These variables are the early life and young adult measures included as covariates and shown in online supplementary appendix tables 2 and 3 . We believe that our approach is reasonable since it has been shown that socioeconomic position and age are the main drivers of selection due to attrition in population surveys in the UK. ${ }^{34} 35$ All models were estimated with the Mplus V. $7^{36}$ software, with the Robust maximum likelihood estimator and Monte Carlo integration.

\section{RESULTS}

The latent class modelling resulted in selection of 6-class models for men and women although the prevalence and composition of the classes differed by gender. Full details of the specification of these models (information criteria, likelihood based tests the classification/allocation quality) have been previously described. ${ }^{9}$ Figures 1 and 2 show the probabilities of marriage, cohabitation and remarriage in the six classes for men and women. For men, class 1 is the most prevalent $(\mathrm{N}=3073,61.8 \%)$ and is characterised by those who married by their 20 s or early 30 s and remained married. Class $2(\mathrm{~N}=411,8.3 \%)$ comprises men married by their 20 s or early 30 s, but later divorced, with increasing cohabitation but little remarriage by their $40 \mathrm{~s}$. Class $3(\mathrm{~N}=373,7.5 \%)$ includes men most of whom cohabited from their late 20 s or early 30 s onwards but never married. Class 4 $(\mathrm{N}=467,9.4 \%)$ comprises men who typically cohabitated in their early $30 \mathrm{~s}$, married in their mid or late $30 \mathrm{~s}$ and remained married. Class $5(\mathrm{~N}=94,1.9 \%)$ includes men who divorced in their mid to late 30 s but later remarried, with some cohabitation in between. Finally, class $6(\mathrm{~N}=553,11.1 \%)$ consists almost exclusively of men who never married or cohabited.

Among women, the most prevalent class $(\mathrm{N}=2209,42 \%)$ comprises those who married by their early 20 s and remained so up to age 44 . Class $2(\mathrm{~N}=1215,23.1 \%)$ includes women who married later (in their late 20 s or early 30 s) and remained married. Class $3(\mathrm{~N}=429,8.1 \%)$ is characterised by women who never married or married by their 20 s and subsequently separated, and who were more likely to cohabit from their early 30 s onwards. Women allocated to class $4(\mathrm{~N}=294,5.6 \%)$ married and subsequently divorced in their 20 s or early 30 s, cohabited and then remarried. Women allocated to class 5 $(\mathrm{N}=457,8.7 \%)$ married by their 20 s or early 30 s but divorced in their mid to late 30 s, with some later cohabiting or remarrying. Class $6(\mathrm{~N}=652,12.4 \%)$ is almost entirely comprised women who married or cohabited.

Table 1 shows the distribution of health behaviours in midlife. Approximately a third of men reported problem drinking (AUDIT Score $>8$ ) compared to $14 \%$ of women, and HED was more frequent in men. Just under a quarter of men and women were current smokers. The prevalence of overweight $(\mathrm{BMI} \geq 25)$ and raised WHR was higher in men than women. On average, men did more hours of physical activity per week but also spent longer in sedentary activities than women. Exploratory analyses showed that health and health behaviours to age 23 were associated with subsequent partnership trajectories (see online supplementary appendix table 4).

Table 2 shows the estimated ORs or incidence rate ratios (IRRs) and CIs for the associations between the longitudinal partner status typologies described above and drinking and smoking outcomes in midlife. Smoking and heavy drinking were more common in unmarried men. Men who got divorced in their late 30s (class 2), cohabited (class 3) or who never married or cohabited (class 6) were more likely to be problem drinkers in midlife when compared to the reference group (men who married in their 20 s or early 30 s and remained married, class 1). HED was more common among men who divorced or cohabited (classes 2, 3 and 5). The odds of being an ex-smoker or current smoker were significantly higher for men who divorced in their late 30s (class 2), cohabited (class 3) or who never partnered (class 6), and these men had the most years of
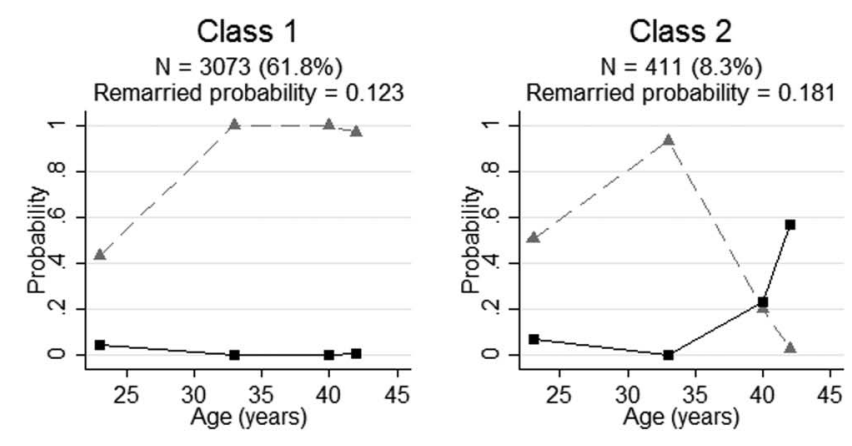

Class 4
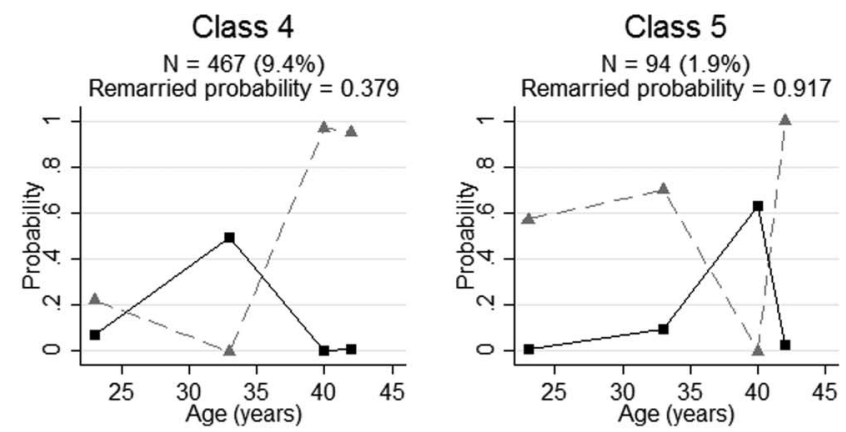
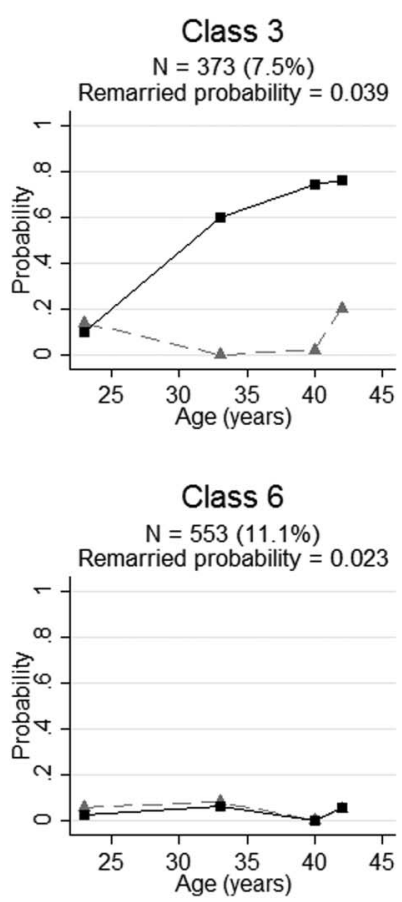
Class 1

$\mathrm{N}=2209(42.0 \%)$

Remarried probability $=0.138$

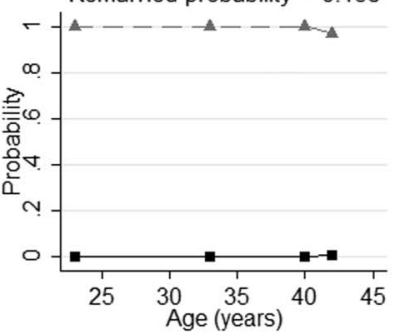

Class 4

$\mathrm{N}=294(5.6 \%)$ Remarried probability $=0.661$

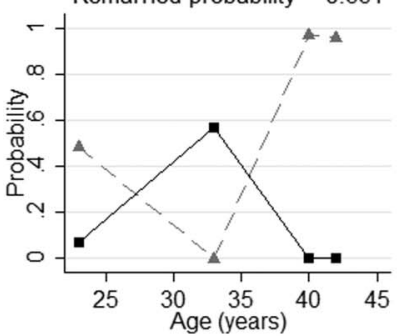

Class 2

$\mathrm{N}=1215(23.1 \%)$

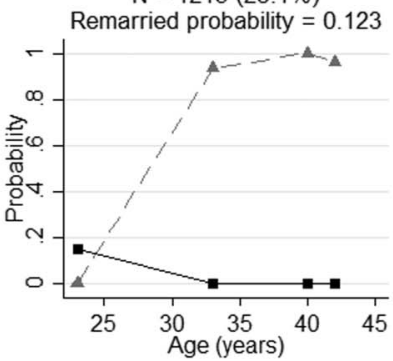

Class 5

$\mathrm{N}=457(8.7 \%)$ Remarried probability $=0.312$

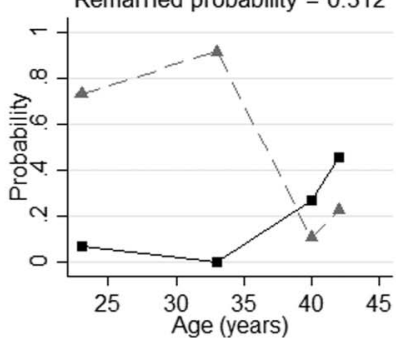

Class 3

$\mathrm{N}=429(8.1 \%)$

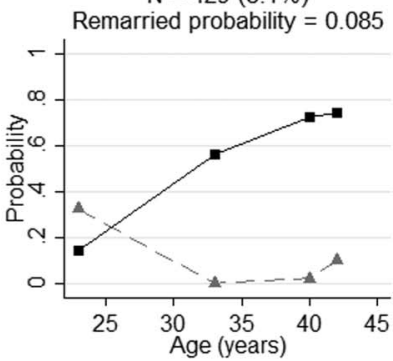

Class 6

$\mathrm{N}=652(12.4 \%)$

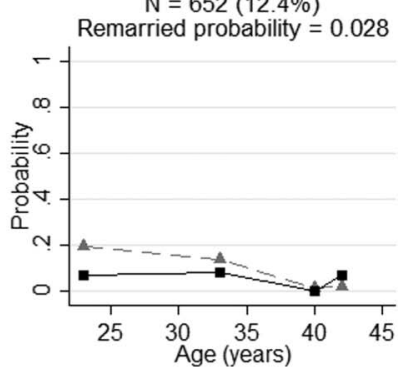

Figure 2 Longitudinal typologies of probability of marriage (dotted grey line) and cohabitation (solid black line) in women (based on data and figures originally published in the American Journal of Public Health ${ }^{9}$ ).

Table 1 Distribution of health behaviours in midlife, men and women, 1958 British Birth Cohort

\begin{tabular}{|c|c|c|c|c|}
\hline & \multicolumn{2}{|c|}{ Men $(\mathrm{N}=4970)$} & \multicolumn{2}{|c|}{ Women $(\mathrm{N}=5256)$} \\
\hline & $\mathrm{N}$ & Per cent & $\mathrm{N}$ & Per cent \\
\hline \multicolumn{5}{|l|}{ AUDIT Score* } \\
\hline$<8$ & 3071 & 65.8 & 4059 & 86.1 \\
\hline 8 or more & 1594 & 34.2 & 653 & 13.9 \\
\hline \multicolumn{5}{|l|}{ Frequency of HED* } \\
\hline Never & 1011 & 23.0 & 2056 & 48.0 \\
\hline Monthly or less & 1269 & 28.9 & 1347 & 31.5 \\
\hline Monthly & 619 & 14.1 & 366 & 8.6 \\
\hline Weekly & 1490 & 34.0 & 513 & 12.0 \\
\hline \multicolumn{5}{|l|}{ Smoking $\dagger$} \\
\hline Never smoked & 2020 & 44.9 & 2136 & 46.6 \\
\hline Ex-smoker or occasional smoker & 1400 & 31.1 & 1321 & 28.8 \\
\hline Current smoker & 1076 & 23.9 & 1126 & 24.6 \\
\hline $\begin{array}{l}\text { Years regular smoking } 23-42 \text {, mean } \\
\text { (SD) }\end{array}$ & 4387 & $5.9(0.12)$ & 4647 & $5.7(0.12)$ \\
\hline \multicolumn{5}{|l|}{$\mathrm{BMI}^{*}$} \\
\hline$<25$ & 1140 & 24.9 & 2027 & 43.8 \\
\hline 25 or more & 3445 & 75.2 & 2598 & 56.2 \\
\hline \multicolumn{5}{|l|}{ Waist/hip ratio* } \\
\hline$<0.90 / 0.85$ & 1421 & 30.7 & 3496 & 74.9 \\
\hline$\geq 0.85 / 0.90$ & 3208 & 69.3 & 1174 & 25.1 \\
\hline $\begin{array}{l}\text { Hours moderate/vigorous physical } \\
\text { activity per week, }{ }^{*} \text { mean (SD) }\end{array}$ & 2873 & $15.4(16.5)$ & 2953 & $9.4(11.4)$ \\
\hline $\begin{array}{l}\text { Hours sedentary behaviour per } \\
\text { week, }^{*} \text { mean (SD) }\end{array}$ & 3632 & $44.2(20.4)$ & 3693 & 17.7 \\
\hline $\begin{array}{l}\text { Index of poor health behaviours } \\
(0-6) \text {, mean }(S D)\end{array}$ & 2701 & $2.4(1.1)$ & 2652 & $1.7(1.1)$ \\
\hline
\end{tabular}

regular smoking, suggesting that they were least likely to quit between ages 23 and 42 .

Among women, those who had divorced in their mid to late 30s (class 5) had higher odds of problem drinking (OR 1.75 (1.37 to 2.59)) and more frequent HED (OR 1.54 (1.27 to 2.08)) compared to the reference group (those who married in their early 20 s and remained married, class 1 ). Women who had never married or cohabited (class 6) also had higher odds of problem drinking. Women who got married later (in their late 20 s or 30 s, class 2 ) had 30 per cent lower odds of smoking and fewer years of regular smoking when compared with women who married earlier. All other classes for women (cohabiting, divorced and never married or cohabited) had significantly higher odds of smoking compared to the reference group.

Table 3 shows the results of regression models for the associations between physical activity, weight, the health behaviour index and the longitudinal partner status typologies. Men in class 2 (divorced and not remarried) were more physically active compared to the reference group (men who married in their 20s or early 30s and remained married, class 1 ) and spent fewer hours of sedentary time per week. Among women, there were no associations between physical activity and partnership status. Women in classes 3 (cohabiting in their 30s) and 6 (never married or cohabited) spent more hours per week in sedentary behaviours when compared with the reference group. Associations with BMI and partnership were similar in men and women. Overall getting married later or not at all was associated with lower odds of being overweight in midlife. There were no significant associations between partnership trajectory and WHR. In men, experiencing divorce (whether they remarried or later cohabited or not-classes 2 and 5) was associated with having a greater number of poor health behaviours (from an index of 6). 
Table 2 ORs/incident rate ratios and $95 \%$ Cls for alcohol use at age 44-46, smoking at age 42 and years of regular smoking according to partnership trajectories

\begin{tabular}{|c|c|c|c|c|}
\hline & $\begin{array}{l}\text { AUDIT Score } \geq 8 \\
\text { OR }(95 \% \mathrm{CI})\end{array}$ & $\begin{array}{l}\text { Frequency of heavy episodic } \\
\text { drinking (ordinal) } \\
\text { OR }(95 \% \mathrm{Cl})\end{array}$ & $\begin{array}{l}\text { Smoking (ordinal) } \\
\text { OR }(95 \% \mathrm{Cl})\end{array}$ & $\begin{array}{l}\text { Years of regular smoking } \\
\text { (age } 23-42) \\
\text { IRR }(95 \% \mathrm{Cl})\end{array}$ \\
\hline \multicolumn{5}{|l|}{ Men $(\mathrm{N}=4970)$} \\
\hline Class 1: Married in 20s/early 30s, married once (REF) & 1.00 & 1.00 & 1.00 & 0.00 \\
\hline Class 2: Divorced at late 30s not remarried & $1.32(1.07$ to 1.82$)$ & 1.21 (1.01 to 1.63$)$ & 1.86 (1.46 to 2.72$)$ & $0.24(0.19$ to 0.32$)$ \\
\hline Class 3: Cohabiting, not married & $1.52(1.23$ to 2.12$)$ & $1.27(1.04$ to 1.73$)$ & 1.55 (1.22 to 2.24$)$ & $0.30(0.24$ to 0.40$)$ \\
\hline Class 4: Married in mid/late 30s, married once & $1.18(0.97$ to 1.62$)$ & $1.02(0.86$ to 1.34$)$ & $1.08(0.86$ to 1.53$)$ & $0.09(0.03$ to 0.19$)$ \\
\hline Class 5: Divorced in 30s, later remarried & 1.33 (0.89 to 2.51$)$ & $1.55(1.10$ to 2.63$)$ & $1.22(0.78$ to 2.49$)$ & $0.01(-0.11$ to 0.20$)$ \\
\hline Class 6: Never married or cohabited & 1.41 (1.16 to 1.89$)$ & $1.16(0.97$ to 1.55$)$ & 1.67 (1.34 to 2.37$)$ & $0.37(0.31$ to 0.46$)$ \\
\hline \multicolumn{5}{|l|}{ Women $(\mathrm{N}=5256)$} \\
\hline Class 1: Married in early 20s, married once (REF) & 1.00 & 1.00 & 1.00 & 0.00 \\
\hline Class 2: Married in late 20s/early 30s, married once & $1.18(0.94$ to 1.68$)$ & 0.97 (0.84 to 1.22$)$ & $0.70(0.59$ to 0.92$)$ & $-0.15(-0.19$ to 0.09$)$ \\
\hline Class 3: Cohabiting, not married & 1.21 (0.91 to 1.91$)$ & $1.19(0.98$ to 1.61$)$ & $1.67(1.31$ to 2.46$)$ & $0.14(0.10$ to 0.20$)$ \\
\hline Class 4: Divorced in 20 s/early 30 s, cohabited or remarried & $1.17(0.83$ to 1.99$)$ & $1.13(0.91$ to 1.59$)$ & $1.46(1.09$ to 2.30$)$ & $0.08(0.03$ to 0.16$)$ \\
\hline Class 5: Divorced in mid/late 30s, not remarried & 1.75 (1.37 to 2.59$)$ & 1.54 (1.27 to 2.08$)$ & $1.57(1.23$ to 2.29$)$ & $0.25(0.21$ to 0.32$)$ \\
\hline Class 6: Never married or cohabited & $1.32(1.03$ to 1.96$)$ & $1.21(1.01$ to 1.59$)$ & $1.28(1.04$ to 1.76$)$ & $0.11(0.08$ to 0.17$)$ \\
\hline \multicolumn{5}{|c|}{$\begin{array}{l}\text { Adjusted for early life socioeconomic position (latent summary of financial hardship during the last year at age } 11 \text {, access to household amenities at age } 11 \text {, paternal social class at age } \\
7 \text {, number of people per room at birth, housing tenure at age } 7 \text { and paternal weekly net pay at age } 16 \text { ), health centre attendance during the last year at age } 16 \text {, disability at age } 16 \text {, } \\
\text { height at age } 7 \text {, cognitive ability at } 11 \text {, parental divorce at age } 16 \text {, behaviour score (age 16), educational attainment at } 23 \text {, social class at } 23 \text {, housing tenure at } 23 \text {, net family income } \\
\text { at } 23 \text {, self-rated health at } 23 \text {, depression at } 23 \text {, employment status at } 23 \text {, presence of long-standing disability at } 23 \text {, height at } 23 \text { (men only); earlier measures of health-related } \\
\text { behaviours-smoking at ages } 16 \text { and } 23 \text {, alcohol use frequency at age } 23 \text {, exercise frequency at age } 23 \text {, BMI at age } 23 \text {. } \\
\text { Results in bold font are statistically significant at the } 5 \% \text { level. } \\
\text { AUDIT, Alcohol Use Disorders Identification Test; BMI, body mass index. }\end{array}$} \\
\hline
\end{tabular}

Table 3 ORs/regression coefficients and $95 \%$ Cls for physical activity, BMI and WHR at age 44-46, and the index of poor health behaviours according to partnership trajectories

\begin{tabular}{|c|c|c|c|c|c|}
\hline Class & $\begin{array}{l}\text { Hours physical } \\
\text { activity per week } \\
\text { B (95\% Cl) }\end{array}$ & $\begin{array}{l}\text { Hours sedentary } \\
\text { time per week } \\
\text { B }(95 \% \mathrm{Cl})\end{array}$ & $\begin{array}{l}\text { BMI } \geq 25 \text { (ref: }<25) \\
\text { OR }(95 \% \mathrm{Cl})\end{array}$ & $\begin{array}{l}\text { Raised WHR } \\
\text { OR }(95 \% \mathrm{Cl})\end{array}$ & $\begin{array}{l}\text { Index of poor } \\
\text { health behaviours } \\
\text { (ordinal) } \\
\text { OR }(95 \% \mathrm{Cl})\end{array}$ \\
\hline \multicolumn{6}{|l|}{ Men $(\mathrm{N}=4970)$} \\
\hline $\begin{array}{l}\text { Class 1: Married in 20s/early 30s, married } \\
\text { once (REF) }\end{array}$ & 0.00 & 0.00 & 1.00 & 1.00 & 1.00 \\
\hline Class 2: Divorced at late 30 s not remarried & $0.29(0.08$ to 0.62$)$ & $-0.08(-0.14$ to 0.01$)$ & 0.94 (0.73 to 1.39$)$ & $1.17(0.93$ to 1.66$)$ & 2.00 (1.58 to 2.52$)$ \\
\hline Class 3: Cohabiting, not married & $-0.14(-0.41$ to 0.29$)$ & $-0.05(-0.10$ to 0.04$)$ & $0.73(0.56$ to 1.08$)$ & $1.12(0.89$ to 1.60$)$ & $1.30(1.01$ to 1.69$)$ \\
\hline Class 4: Married in mid/late 30s, married once & $-0.09(-0.25$ to 0.15$)$ & $0.03(-0.02$ to 0.11$)$ & $0.93(0.73$ to 1.35$)$ & 1.01 (0.82 to 1.38$)$ & 1.06 (0.86 to 1.31$)$ \\
\hline Class 5: Divorced in 30s, later remarried & $-0.50(-1.12$ to 0.47$)$ & $-0.12(-0.25$ to 0.08$)$ & $1.66(0.94$ to 4.04$)$ & $1.42(0.91$ to 2.82$)$ & 1.81 (1.15 to 2.85$)$ \\
\hline Class 6: Never married or cohabited & $-0.31(-0.50$ to 0.00$)$ & $-0.09(-0.15$ to 0.00$)$ & $0.56(0.44$ to 0.80$)$ & $1.06(0.87$ to 1.45$)$ & 1.10 (0.88 to 1.36$)$ \\
\hline \multicolumn{6}{|l|}{ Women $(\mathrm{N}=5256)$} \\
\hline $\begin{array}{l}\text { Class 1: Married in early 20s, married once } \\
\text { (REF) }\end{array}$ & 0.00 & 0.00 & 1.00 & 1.00 & 1.00 \\
\hline $\begin{array}{l}\text { Class 2: Married in late 20s/early 30s, married } \\
\text { once }\end{array}$ & $-0.14(-0.27$ to 0.07$)$ & $-0.03(-0.08$ to 0.04$)$ & $0.71(0.6$ to 0.93$)$ & $0.96(0.81$ to 1.27$)$ & $0.86(0.73$ to 1.03$)$ \\
\hline Class 3: Cohabiting, not married & $-0.08(-0.27$ to 0.21$)$ & $0.09(0.02$ to 0.20$)$ & $0.71(0.56$ to 1.05$)$ & $0.92(0.73$ to 1.33$)$ & $0.99(0.77$ to 1.27$)$ \\
\hline $\begin{array}{l}\text { Class 4: Divorced in 20s/early 30s, cohabited } \\
\text { or remarried }\end{array}$ & $0.06(-0.15$ to 0.39$)$ & $0.02(-0.05$ to 0.14$)$ & 0.76 (0.58 to 1.17$)$ & 0.85 (0.63 to 1.34$)$ & 1.00 (0.75 to 1.32$)$ \\
\hline $\begin{array}{l}\text { Class 5: Divorced in mid/late 30s, not } \\
\text { remarried }\end{array}$ & $0.02(-0.15$ to 0.28$)$ & $0.06(0.00$ to 0.15$)$ & $0.70(0.56$ to 1.00$)$ & $0.93(0.74$ to 1.32$)$ & $1.07(0.85$ to 1.33$)$ \\
\hline Class 6: Never married or cohabited & $-0.04(-0.22$ to 0.24$)$ & $0.13(0.07$ to 0.22$)$ & 0.80 (0.64 to 1.11$)$ & 1.14 (0.93 to 1.56$)$ & $0.89(0.72$ to 1.11$)$ \\
\hline
\end{tabular}

We also fitted nested regression models that compared the unadjusted estimates with those adjusted for different groups of confounders (results not shown). For smoking and drinking, the most substantial changes to the associations occurred when we added measures of smoking or drinking at age 23. For the other health behaviour outcomes, there was very little change. 


\section{DISCUSSION}

The behavioural risk factors smoking, alcohol use, high BMI and physical inactivity together account for the vast majority of disease burden in the UK, ${ }^{37}$ and a better understanding of lifecourse social determinants of these factors is important to devise strategies for reducing the burden of preventable morbidity and mortality. In this study, life-course partnership trajectories were prospectively associated with harmful health behaviours in midlife, even after adjustment for a range of socioeconomic, psychosocial and health-related factors in childhood and early adulthood. The patterns varied somewhat by gender and the health behaviour considered, but overall being divorced, or having never married or cohabited was associated with poorer outcomes. Problem drinking, heavy drinking and smoking were more common in men and women who divorced in their 30s or those who had never married or cohabited. In general, marriage (and remarriage in men) was associated with having a higher BMI, consistent with previous research. ${ }^{16}$ Later marriage in women was associated with less chance of smoking and being overweight. Physical activity was less clearly patterned by partnership history, although men and women who had never entered a partnership exercised less often and for less time. Men who divorced in their 30s but did not remarry had higher levels of physical activity compared to men who remained married. That partnership had opposite, potentially offsetting, associations with smoking, drinking, BMI and physical activity means that the co-occurrence of poor health behaviours was only statistically significant for divorced men.

The associations between partnership history and health behaviours are partly consistent with the patterns found with objectively measured biomarkers in our previous study ${ }^{9}$ and other studies of health and mortality ${ }^{1-7} 38$ and suggest that health behaviours explain at least some of the association between partnership history and health. Never partnered and divorced individuals exhibited the worst health in terms of drinking and smoking, and this is in line with raised levels of haemostatic biomarkers and worse respiratory functioning found in this cohort. ${ }^{9}$ The main exceptions were that smoking and heavy drinking were more common among divorcees and cohabiters, but this was not reflected in poorer measures on inflammatory and haemostatic biomarkers. Potential explanations for this could be reporting bias by marital status for health behaviours, or that the harmful effect of drinking and smoking in the divorced and cohabiters could be offset, for at least some health markers, by lower prevalence of overweight and weight gain.

Previous studies have suggested that the health benefits of marriage are greater for men than women partly because men's health-related behaviours are influenced to a greater extent by social control from wives. ${ }^{39}$ In this study, the association between partnership and health behaviours was broadly similar in men and women for smoking, drinking and BMI, however as the prevalence of some behaviours (such as heavy drinking) was much higher among men, the absolute impact of marriage pattern would be greater. The 'social control' thesis did not appear to operate to the same extent for cohabiting relationships. This could be related to other factors such as child bearing or lifetime socioeconomic status (which were not included here because on the causal pathway) or because those choosing cohabitation rather than marriage have a different type of relationship; this deserves further analysis. Remarried people had similar profiles to those in first marriages for some health behaviours (smoking and BMI in men, and physical activity), which is consistent with previous studies and suggests that the some of the negative effects of midlife marital disruption are short term. ${ }^{22}$
The contribution of this study is our consideration of a 21-year longitudinal partnership trajectory that includes marriage, cohabitation and remarriage in explaining health behaviour inequalities in midlife, which has been shown to be superior to current marital status. ${ }^{578}$ In addition, we were able to include many prospective measures of health, socioeconomic and psychosocial factors that may influence selection. Our measures of health behaviours were collected using validated instruments for problem drinking and physical activity, prospectively measured smoking history and objective measures for adiposity. The limitations of this study were that many of our outcome measures and covariates and reports of marriage and cohabitation were self-reported and the possibility of reporting bias influencing our findings cannot be excluded. We did not have information on partnership status between follow-up occasions, so there is a possibility of unaccounted marital transitions. As in any observational study, there is always the chance of unknown, and therefore unaccounted for, confounders. Attrition within the cohort study and high non-response for some items-particularly physical activity-meant that we did not have complete data and rely on the (theoretically untestable) MAR assumption when estimating the models. The relationship between health behaviours and partnership status is likely to be dynamic, so further research could explicitly model this interaction. Previous research has shown that many health behaviours are concordant between partners, ${ }^{20}$ but unfortunately we could not investigate this issue using these data as information on partners was lacking. Health behaviours constitute only one of several potential mechanisms linking partnership and health, and the contribution of differing patterns of social support, wealth and fertility (some of which could operate as mediators) needs to be considered to understand the total health effect in midlife.

The study provides evidence that life-course partnership history is associated with patterns of midlife health behaviours, which likely accounts for some of the differences in health status found previously. However, this is a relatively young cohort, and longer follow-up is required to fully assess the impact of partnership on health outcomes. The partnership

\section{What is already known on this subject}

In many settings, being married is associated with better long-term health outcomes than being formerly married or never married. A consideration of life-course partnership history (rather than just current marital status) is important. The extent to which health behaviours are patterned by partnership biography, and their role as an explanatory mechanism in the association with health status remains unclear.

\section{What this study adds}

Longitudinal partnership trajectories (particularly experience of divorce, cohabitation and being never partnered) are associated with a range of unhealthy behaviours in midlife. Differences in health behaviours probably account for much of the association between partnership trajectories and health. Attempts to prevent or modify harmful health behaviours should take account of social factors such as partnership. 
behaviour in our study occurred from 1981 to 2002, but it is important to consider our results within the context of changing patterns of partnership for these and subsequent cohorts in the $\mathrm{UK}$, especially increases in the incidence and duration of premarital cohabitation. ${ }^{40}$ Moreover, as cohabitation becomes more normalised and less 'deviant', the association with some unhealthy behaviours could diminish. In this study, our aim was to better understand the health benefits of partnership in general, but in addition our results highlight the excess public health risk associated with remaining single or becoming separated, which appears to operate mainly through excessive alcohol use and smoking. This suggests a need for a greater awareness on the part of health professionals that some individuals may need additional social or psychological support to maintain or develop healthy habits, avoid drinking heavily and quit smoking. It also raises a concern for health and healthcare planning as life-course partnership trajectories continue to change.

Acknowledgements The authors are grateful to the Centre for Longitudinal Studies (CLS), UCL Institute of Education for the use of these data and to the UK Data Service for making them available.

Contributors GBP designed the study. KK undertook the analysis and wrote the first draft. EG, GBP and RJS provided comments on subsequent versions.

Funding The research leading to these results has received funding from the European Research Council under the European Union's Seventh Framework Programme (FP7/2007-2013)/ ERC grant agreement n 324055.

Competing interests None declared.

Ethics approval NHS NRES Committee London-Central.

Provenance and peer review Not commissioned; externally peer reviewed.

Open Access This is an Open Access article distributed in accordance with the Creative Commons Attribution Non Commercial (CC BY-NC 4.0) license, which permits others to distribute, remix, adapt, build upon this work non-commercially, and license their derivative works on different terms, provided the original work is properly cited and the use is non-commercial. See: http://creativecommons.org/ licenses/by-nc/4.0/

\section{REFERENCES}

1 Hu YR, Goldman N. Mortality differentials by marital status: an international comparison. Demography 1990;27:233-50.

2 Gove WR. Sex, marital status, and mortality. AJS 1973;79:45-67.

3 Murphy M, Glaser K, Grundy E. Marital status and long-term illness in Great Britain. J Marriage Fam 1997;59:156-64.

4 Murphy M, Grundy E, Kalogirou S. The increase in marital status differences in mortality up to the oldest age in seven European countries, 1990-99. Popul Stud 2007;61:287-98.

5 Grundy EM, Tomassini C. Marital history, health and mortality among older men and women in England and Wales. BMC Public Health 2010;10:554

6 Kravdal $\varnothing$, Grundy E, Lyngstad TH, et al. Family life history and late mid-life mortality in Norway. Popul Dev Rev 2012;38:237-57.

7 Hughes ME, Waite LJ. Marital biography and health at mid-life. J Health Soc Behav 2009:50:344-58.

8 McFarland MJ, Hayward MD, Brown D. I've got you under my skin: marital biography and biological risk. J Marriage Fam 2013;75:363-80.

9 Ploubidis GB, Silverwood RJ, DeStavola B, et al. Life-course partnership status and biomarkers in midlife: evidence from the 1958 British Birth Cohort. Am J Public Health 2015;105:1596-603.

10 Joung IM, van de Mheen HD, Stronks K, et al. A longitudinal study of health selection in marital transitions. Soc Sci Med 1998:46:425-35.

11 Murray JE. Marital protection and marital selection: evidence from a historical-prospective sample of American men. Demography 2000;37:511-21.
12 Lillard LA, Waite LJ. Til death do us part: marital disruption and mortality. AJS 1995:100:1131-56.

13 Ben-Shlomo Y, Smith GD, Shipley M, et al. Magnitude and causes of mortality differences between married and unmarried men. J Epidemiol Community Health 1993;47:200-5

14 Martikainen P, Valkonen T. Mortality after the death of a spouse: rates and causes of death in a large Finnish cohort. Am J Public Health 1996;86:1087-93.

15 Leonard KE, Rothbard JC. Alcohol and the marriage effect. J Stud Alcohol Suppl 1999;13:139-46.

16 Eng PM, Kawachi I, Fitzmaurice G, et al. Effects of marital transitions on changes in dietary and other health behaviours in US male health professionals. J Epidemiol Community Health 2005;59:56-62.

17 Lee $\mathrm{S}$, Cho E, Grodstein $\mathrm{F}$, et al. Effects of marital transitions on changes in dietary and other health behaviours in US women. Int J Epidemiol 2005;34:69-78.

18 Wyke S, Ford G. Competing explanations for associations between marital status and health. Soc Sci Med 1992;34:523-32.

19 Joung IM, Stronks K, van de Mheen $\mathrm{H}$, et al. Health behaviours explain part of the differences in self reported health associated with partner/marital status in the Netherlands. J Epidemiol Community Health 1995:49:482-8.

20 Meyler D, Stimpson JP, Peek MK. Health concordance within couples: a systematic review. Soc Sci Med 2007:64:2297-310.

21 Schone BS, Weinick RM. Health-related behaviors and the benefits of marriage for elderly persons. Gerontologist 1998;38:618-27.

22 Williams K, Umberson D. Marital status, marital transitions, and health: a gendered life course perspective. J Health Soc Behav 2004;45:81-98.

23 Rhodes RE, Mark RS, Temmel CP. Adult sedentary behavior: a systematic review. Am J Prev Med 2012;42:e3-e28.

24 Power C, Elliott J. Cohort profile: 1958 British birth cohort (National Child Development Study). Int J Epidemiol 2006;35:34-41.

25 Babor TF, Biddle-Higgins JC, Saunders JB, et al. AUDIT-the alcohol use disorders identification test: guidelines for use in primary care. 2nd edn. Geneva: World Health Organisation, 2001.

26 Wareham NJ, Jakes RW, Rennie KL, et al. Validity and repeatability of the EPIC-Norfolk Physical Activity Questionnaire. Int J Epidemiol 2002;31:168-74.

27 Ainsworth BE, Haskell WL, Whitt MC, et al. Compendium of physical activities: an update of activity codes and MET intensities. Med Sci Sports Exerc 2000;32(Suppl 1):\$498-504.

28 World Health Organisation, Waist circumference and waist-hip ratio: report of a WHO expert consultation. Geneva: World Health Organisation, 2011.

29 Nagin DS, Tremblay RE. What has been learned from group-based trajectory modeling? Examples from physical aggression and other problem behaviors. Ann Am Acad Pol Soc Sci 2005:602:82-117.

30 Mavandadi S, Rook KS, Newsom JT. Positive and negative social exchanges and disability in later life: An investigation of trajectories of change. J Gerontol B Psychol Sci Soc Sci 2007;62:S361-70.

31 Sturgis $\mathrm{P}$, Sullivan L. Exploring social mobility with latent trajectory groups. J $R$ Stat Soc Ser A Stat Soc 2008;171:65-88.

32 Enders CK. A Primer on maximum likelihood algorithms available for use with missing data. Struct Equ Modeling 2001;8:128-41.

33 Little RJA, Rubin DB. Statistical analysis with missing data. 2nd edn. Chichester: Willey, 2002.

34 Noah Uhrig S. The nature and causes of attrition in the British Household Panel Survey. Institute for Social and Economic Research, 2008.

35 Durrant G, Goldstein H. Analysing the probability of attrition in a longitudinal survey. Southampton: Statistical Sciences Research Institute, 2008.

36 Muthen LK, Muthen BO. Mplus user's guide. 7th edn. Los Angeles, CA : Muthén \& Muthén, 1998-2012.

37 Murray CJ, Richards MA, Newton JN, et al. UK health performance: findings of the Global Burden of Disease Study 2010. Lancet 2013;381:997-1020.

38 Martikainen $\mathrm{P}$, Martelin T, Nihtilä E, et al. Differences in mortality by marital status in Finland from 1976 to 2000: analyses of changes in marital-status distributions, socio-demographic and household composition, and cause of death. Popul Stud (Camb) 2005;59:99-115.

39 Umberson D. Gender, marital status and the social control of health behavior. Soc Sci Med 1992;34:907-17.

40 Beaujouan É, Bhrolcháin MN. Cohabitation and marriage in Britain since the 1970s. In: Probert R, ed. Cohabitation and non-marital births in England and Wales, 1600-2012. London, UK: Palgrave Macmillan, 2014:192-213. 